\title{
DETERMINANTES DE ESTRUTURA DE CAPITAL NO MERCADO BRASILEIRO - ANÁLISE DE REGRESSÃO COM PAINEL DE DADOS NO PERÍODO 1999-2003
}

\section{DETERMINANT FACTORS OF CAPITAL STRUCTURE IN THE BRAZILIAN MARKET - AN ANALYSIS OF THE REGRESSION WITH DATA COVERING THE PERIOD FROM 1999 TO 2003}

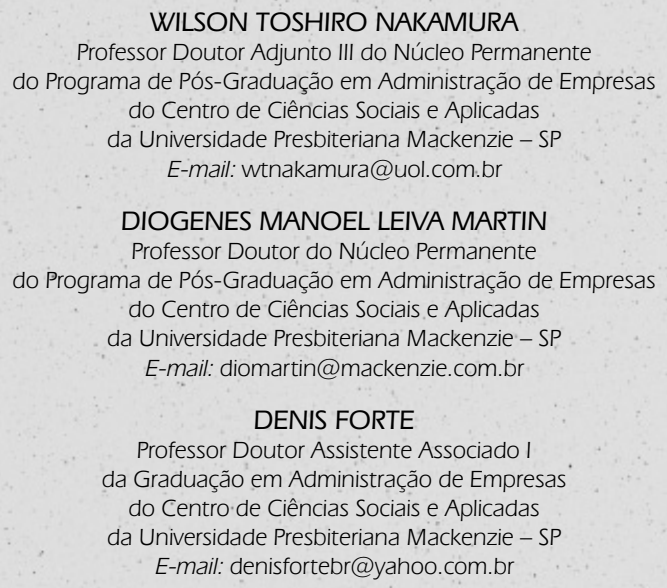

WILSON TOSHIRO NAKAMURA

Professor Doutor Adjunto III do Núcleo Permanente do Programa de Pós-Graduação em Administração de Empresas. do Centro de Ciências Sociais e Aplicadas da Universidade Presbiteriana Máckenzie - SP E-mail:wtnakamura@uol.com.br

DIOGENES MANOEL LEIVA MARTIN Professor Doutor do Núcleo Permanente do Programa de Pós-Graduação em Administração de Empresas do Centro de Ciências Sociais e Aplicadas da Universidade Presbiteriana Mackenzie - SP E-mail:diomartin@mackenzie.com.br

DENIS FORTE

Professor Doutor Assistente Associado I

da Graduação em Administração de Empresas do Centro de Ciências Sociais e Aplicadas da Universidade Presbiteriana Mackenzie - SP E-mail: denisfortebr@yahoo.com.br

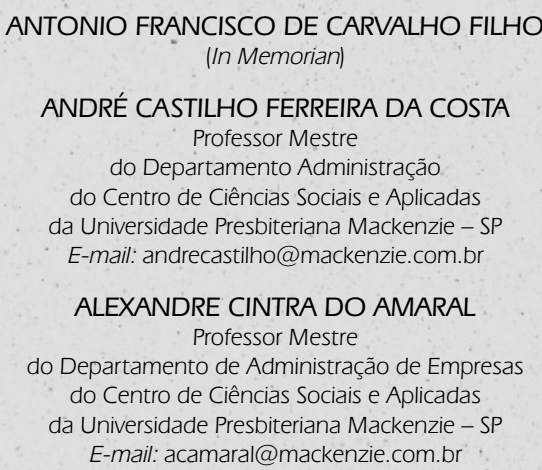

ANTONIO FRANCISCO DE CARVALHO FILHO (In Memorian)

ANDRÉ CASTILHO FERREIRA DA COSTA Professor Mestre

do Departamento Administração

do Centro de Ciências Sociais e Aplicadas da Universidade Presbiteriana Mackenzie - SP E-mail: andrecastilho@mackenzie.com.br

ALEXANDRE CINTRA DO AMARAL Professor Mestre

do Departamento de Administração de Empresas do Centro de Ciências Sociais e Aplicadas da Universidade Presbiteriana Mackenzie - SP E-mail: acamaral@mackenzie.com.br

\section{RESUMO}

Este artigo apresenta os resultados de uma investigação sobre os fatores determinantes da estrutura de capital das companhias abertas que atuam no mercado brasileiro. Foi utilizada uma amostra de 91 empresas cobrindo $o$ período de 1999 a 2003. Na realização deste trabalho foi utilizada uma técnica de estimativa mais forte, conjugando Panel Data Dinâmico, que combina dados de corte transversal com séries temporais, com um instrumento de método de momento generalizado. Como proxies de estrutura de capital e alavancagem, foram usados os conceitos contábil e de mercado e seus resultados foram comparados. Em consonância com a literatura da área, foram selecionadas as seguintes variáveis: liquidez corrente, tamanho da empresa, rentabilidade, oportunidade de crescimento, risco de negócio, economia fiscal e crescimento de vendas, tangibilidade, coeficiente de variação e risco de falência. Para os testes, foram utilizados os instrumentos econométricos de GMM e AH. Os resultados econométricos demonstraram-se robustos pelas técnicas utilizadas. Os resultados de análise obtidos foram bastante consistentes com as teorias de Pecking Order e de Trade-off. Esses resultados, também, estão em linha com os observados em estudos similares realizados em diversos países.

Palavras-chave: Estrutura de Capital; Painel de Dados Dinâmico; Teoria de Trade-off; Teoria do Pecking Order.

\section{ABSTRACT}

This article presents the results of an investigation about the determinant factors of the capital structure of publicly held companies that operate in the Brazilian market. The sample group consisted of 91 companies, covering the period from 1999 to 2003. A stronger estimation technique conjugating Dynamic Panel Data, which combines cross-section data with time-series, with a generalized method of moments (GMM) tool was used in the performance of this study. The accounting and market concepts were used as capital structure and leverage proxies, and their results were compared. In conformity with literature from the area, the following variables were selected: current ratio, company size, return, growth opportunity, business risk, fiscal economy and sales growth, tangibility, coefficient of variation and barkruptcy risk. The GMM and AH econometric tools were used for the tests. The econometric results proved robust due to the techniques used. The analysis results obtained were largely consistent with the Pecking Order and Trade-off theories. These results are also in line with the results observed in similar studies carried out in several countries.

Keywords: Capital Structure; Dynamic Panel; Trade-off Theory; Pecking Order Theory. 


\section{INTRODUÇÃO}

A questão dos fatores que determinam o endividamento das empresas tem sido a mais explorada em trabalhos acadêmicos sobre estrutura de capital, seja por conta do amplo arcabouço teórico desenvolvido nessa área, seja por conta do grande interesse que essa temática desperta entre os praticantes.

Diversas variáveis já foram testadas, com base em diferentes metodologias estatísticas e econométricas, sendo a grande maioria trabalhos que utilizam dados em corte transversal (cross section) e aplicam métodos tradicionais de regressão linear múltipla. Como variável básica de estudo, comumente se toma o endividamento geral da empresa, seja dividindo o total de dívidas da empresa pelo ativo total, seja dividindo o total de dívidas pelo patrimônio líquido. De acordo com a teoria, normalmente é mais correto trabalhar-se com dados baseados em valores de mercado do ativo e do patrimônio líquido, o que habitualmente não é feito, principalmente em estudos realizados no Brasil, pelas naturais limitações existentes em nosso mercado, seja por conta do relativamente pequeno número de empresas de capital aberto, seja por conta da baixa liquidez da maioria das ações registradas na Bolsa.

Quanto ao que seja estrutura de capital, predomina a idéia de que estrutura de capital corresponde somente às fontes de longo prazo. No entanto, conforme Brealey e Myers (2003), pode ser correto considerar dívidas de curto prazo, também, fazendo parte da estrutura de capital, particularmente em países em que tais obrigações de curto prazo preenchem um papel que deveria ser ocupado por obrigações de longo prazo, caso as condições institucionais e econômicas, assim, o permitissem.

A busca da identificação dos fatores que determinam o endividamento tem implícita a idéia de que deve existir um nível ótimo de endividamento das empresas que deve ser perseguido através do estabelecimento de políticas de estrutura de capital de longo prazo. À medida que existe um nível ótimo de endividamento, torna-se interessante identificar que fatores predominantes explicam a forma como as empresas determinam sua estrutura de capital. $O$ conhecimento de tais fatores atende a dois objetivos dis- tintos, porém inter-relacionados. Em primeiro lugar, permite analisar a validade empírica das teorias sobre estrutura de capital desenvolvidas ao longo do tempo. Em segundo lugar, fornece aos administradores indicações claras sobre que fatores devem ser levados em conta no desenho prático da política de estrutura de capital das empresas.

Desde o trabalho seminal de Modigliani e Miller (1958), tem-se discutido na literatura acadêmica a relevância ou não de políticas de estrutura de capital. Embora em seu trabalho original, Modigliani e Miller tenham concluído pela irrelevância da política de estrutura de capital, há que se ter em conta que tal conclusão foi tomada considerando condições simplificadas de um mercado de capitais perfeito. Nos tempos atuais, ao mesmo tempo em que se cultua o trabalho pioneiro de Modigliani e Miller como um marco no campo da teoria de finanças corporativas e de avaliação de empresas, também tem-se consciência de que é mais provável que exista sim um nível ótimo de endividamento, que seria determinado pela combinação de fatores indicados pela teoria.

A suposta existência de um nível ótimo de endividamento das empresas não exclui a possibilidade de que possa haver outras razões, teóricas ou práticas, que expliquem a forma como as empresas definem seu composto de capital. A teoria do Pecking Order, por exemplo, baseia-se na idéia de que os administradores se pautam por uma hierarquia para definir que recursos serão utilizados para financiar seus projetos. Mesmo que os administradores sigam tal hierarquia não fica invalidada a idéia de um nível ótimo de endividamento na linha proposta pela denominada teoria do Trade-off.

Desenvolveu-se um estudo sobre determinantes do endividamento empresarial tomando uma amostra de empresas brasileiras de capital aberto, abrangendo diferentes setores da economia, regulados ou não, aplicando o método denominado de panel data. Este estudo baseou-se no rol de variáveis definido por Gaud, Jani, Hoesli e Bender (2005), que elaboraram um trabalho recente fazendo uso, também, de dados em painel e tomando por base uma amostra representativa de empresas suíças.

\section{OBJETIVO DO TRABALHO}

O presente trabalho propôs-se a estudar, na realidade empresarial brasileira e tomando um período recente (de 1999 a 2003), quais fatores explicam o endividamento das empresas. Para tanto recorreu-se a uma metodologia moderna do ponto de vista econométrico, denominada de panel data.

O uso de panel data ainda é bastante restrito no Brasil, particularmente nos estudos abordando determinantes da estrutura de capital. Terra (2002) desenvolveu um estudo a respeito de empresas latino-americanas e tomando algumas variáveis que também foram utilizadas neste trabalho, porém mensuradas de forma diferente. Miguel e Pindado (2001) e Gaud, Jani, Hoesli e Bender (2005), também, desenvolveram estudos sobre determinantes da estrutura de capital utilizando-se de panel data e tratando de empresas espanholas e suíças, respectivamente. Especialmente esse último trabalho, mais recente e baseado numa metodologia mais sofisticada, serviu de base para definição das variáveis dependentes e independentes deste estudo, bem como das análises e testes econométricos a serem realizados.

Este estudo pode ser colocado nos seguintes termos, considerando a variável objeto de estudo e as variáveis 
supostamente com conteúdo explicativo para os objetivos que se pretende alcançar:

\section{Endividamento $=f($ liqcorr,size,prof,mtb,pld,ecnd,crescvda $)$}

em que: liqcoor = índice de liquidez corrente da empresa; size $=$ tamanho da empresa; $p r o f=$ rentabilidade operacional da empresa; $m t b=$ potencial de crescimento da empresa; $p l d=$ risco, medido pela volatilidade do lucro; ecnd $=$ economia de impostos; crescuda $=$ taxa de crescimento de vendas.

A maioria dos estudos sobre determinantes de estrutura de capital testam, basicamente, duas teorias, a saber, a teoria do Trade-off e a teoria do Pecking Order. A teoria do Trade-off está baseada nas economias fiscais relacionadas ao uso de dívidas e aos custos de falência esperados. Se forem juntados aos custos de falência esperados, os custos de agência que decorrem do uso excessivo de dívidas, pode-se considerar uma teoria do Trade-off expandida, tratando os custos de falência esperados mais os custos de agência esperados como custos de dificuldades financeiras. Nesse caso, ganham importância variáveis que expressem a utilidade das dívidas para fins de economia fiscal, bem como variáveis que expressem a magnitude dos custos de dificuldades financeiras esperados, tais como liquidez corrente, estimativa dos custos de falência esperados, volatilidade dos retornos operacionais e potencial de crescimento da empresa.

A teoria do Pecking Order, por sua vez, está baseada numa hierarquia de preferências em relação a recursos externos e internos, havendo uma preferência por recursos internos, dada a existência de assimetria de informação no mercado e custos de transação relevantes na colocação de títulos. Portanto, as empresas mais rentáveis operacionalmente e que, por conseqüência, geram mais caixa operacional, deveriam ser menos endividadas. Também, segundo Myers (1977), empresas com oportunidades de crescimento podem investir subotimamente e, portanto, os credores serão mais relutantes em emprestar por períodos longos.

\section{REFERENCIAL TEÓRICO}

Desde o artigo célebre de Modigliani e Miller (1958), em que propuseram a irrelevância das decisões de estrutura de capital sob as condições de um mercado de capitais perfeito, muitos estudos têm sido realizados, adotando abordagens mais teóricas ou mais empíricas.

Embora a maioria dos trabalhos já publicados tenha tomado por base a realidade empresarial e de mercado norte-americana, muitos estudos já foram feitos abordando empresas européias (inglesas, francesas, alemãs, suíças, espanholas etc.), bem como empresas da América Latina, nesse caso principalmente brasileiras.

No artigo de 1958, Modigliani e Miller, dois professores ganhadores de Prêmio Nobel por conta de suas contribuições no campo das finanças corporativas, consideraram as condições prevalecentes num mercado de capitais perfeito, ou seja, inexistência de impostos, custos de transação e custos de falência, inexistência de problemas de agência e de assimetria de informação, bem como acesso ilimitado a crédito no mercado a uma taxa de juros livre de risco.

Considerando o mercado perfeito, Modigliani e Miller propuseram que tanto faz estabelecer um nível alto ou baixo de endividamento do ponto de vista de afetar o valor de mercado da empresa, pois o que determina tal valor são as decisões tomadas em relação ao lado esquerdo do balanço, ou seja, aquelas relacionadas às decisões de investimento. $\mathrm{O}$ argumento de endividamento feito em casa pode ser utilizado para provar que qualquer que seja o endividamento da empresa, qualquer indivíduo pode, comprando ações no mercado e emprestando ou tomando emprestado à taxa de juros livre de risco, reproduzir padrões de fluxo de caixa aos seus acionistas equivalentes aos pagos por uma empresa pouco ou muito endividada.
Modigliani e Miller, também, estabeleceram no artigo de 1958 a relação linear e positiva entre grau de endividamento e taxa de retorno esperada pelos acionistas, relação essa que também se aplica no caso do beta das ações, revelando a plena compatibilidade entre as lógicas do Capital Asset Pricing Model (CAPM) de Sharpe (1964) e Lintner (1965) e do modelo de irrelevância de Modigliani e Miller.

Foram, também, Modigliani e Miller (1963) que chamaram a atenção para a importância dos impostos corporativos nas decisões de estrutura de capital. À medida que se considera um mercado em que há impostos sobre o lucro das empresas, chega-se facilmente à conclusão de que as empresas deveriam trabalhar com grandes proporções de dívidas, por conta da vantagem fiscal decorrente do fato de que os juros, que remuneram as dívidas, são dedutíveis para fins de imposto de renda, o que não acontece com os fluxos de caixa pagos para os acionistas, principalmente os dividendos.

Foi a partir da combinação de economias fiscais decorrentes do uso de dívidas e custos de falência esperados decorrentes do excesso de endividamento, que se estabeleceu o que veio a ser chamada de teoria do Trade-off. De acordo com tal teoria, dois fatores em particular influenciam as decisões de endividamento das empresas: por um lado as economias fiscais esperadas pelo uso crescente de dívida e, por outro, os custos de falência esperados que se manifestam para níveis elevados de endividamento, a partir do qual se tornam maiores quanto mais endividada for a empresa. Os custos de falência podem ser diretos ou indiretos e os indiretos possivelmente os mais relevantes, embora difíceis de serem mensurados. Tais custos indiretos se relacionam às perdas de vendas junto a clientes, redução de prazos junto a fornecedores de bens e serviços, aumento do custo financeiro exigido pelos credores etc. 
Shapiro (1989) e Titman (1984) argumentam que os custos indiretos de falência tendem a ser mais altos para algumas empresas, dependendo do tipo de produto que a empresa produz e vende. Os custos indiretos de falência tendem a ser mais altos para empresas que produzem bens duráveis, produtos que exigem suporte e assistência posterior, produtos que dependem da qualidade percebida antecipadamente e produtos que dependem de outros produtos suplementares fornecidos por terceiros.

Ainda de acordo com a teoria do Trade-off, empresas que possuem maior risco de negócio, que pode ser medido pela volatilidade dos resultados ou dos retornos operacionais, tendem a estar mais expostas a situações de falência ou concordata, devendo, dessa forma, serem menos endividadas do que a média.

A teoria do Trade-off não considera explicitamente mas também não nega a existência de problemas de agência relacionados às decisões de estrutura de capital. Os problemas de agência decorrem das diferenças de interesses entre os diferentes interessados sobre o desempenho da empresa (JENSEN e MECKLING, 1976). No caso das decisões de estrutura de capital, tanto os conflitos de interesse entre acionistas e administradores, quanto entre acionistas e credores têm implicações para tais decisões.

No que se refere aos conflitos de interesses entre acionistas e administradores, tem sido destacado na literatura financeira que quando existe uma forte separação entre proprietários e administradores da empresa, os primeiros recorrem ao uso de dívidas como instrumento de disciplina dos últimos, à medida que empresas mais endividadas exigem uma administração mais eficiente e equilibrada do ponto de vista de gastos e investimentos. Supostamente, tendo obrigações financeiras a cumprir relacionadas a dívidas contraídas, os administradores da empresa procurariam tomar decisões de investimento que efetivamente apresentassem como estimativa valores presentes líquidos (VPLs) positivos, deixando de lado objetivos de crescimento a qualquer custo e de busca de benefícios indiretos através do exercício do cargo que ocupam.

No tocante aos conflitos de interesse entre acionistas e credores, ao contrário, o uso excessivo de dívidas gera custos, denominados custos de agência, que aumentam quanto maior for o endividamento da empresa. Os custos de agência manifestam-se através de gastos com monitoramento relacionados, especialmente, ao cumprimento de cláusulas restritivas inseridas nos contratos de financiamento e nas escrituras de emissão de títulos. Os custos de agência, também, ocorrem em função de decisões subótimas tomadas no contexto das decisões de investimento, financiamento e distribuição de lucros. O temor de expropriação de riqueza da parte dos acionistas que tem forte influência na administração da empresa, faz com que os credores incorporem uma compensação em termos de um maior custo financeiro implícito nas taxas de juros cobradas de empresas consideradas excessivamente endividadas. Uma situação concreta de expropriação de riqueza que pode ocorrer caso não haja restrições contratuais diz respeito à mudança do padrão de risco da empresa, elevando-o, por exemplo, por conta de uma nova divida não esperada e que subtrai riqueza dos credores antigos a favor dos acionistas.

O reconhecimento dos problemas de agência na relação entre acionistas e credores faz com que os credores, de uma forma geral, prefiram emprestar para empresas que possuam ativos que sejam mais fáceis de monitorar e avaliar. Não por acaso, empresas baseadas em bens tangíveis, com relativa facilidade de avaliação e venda tendem a ter maior capacidade de endividamento, tal como ocorre com empresas industriais cuja estrutura de ativos está principalmente baseada em construções, máquinas, equipamentos e instalações. Conforme Damodaran (2001), empresas do setor farmacêutico tendem a ser menos endividadas, justamente por conta dos altos investimentos para desenvolvimento de novos produtos que demandam muitos anos até que os produtos sejam comercializados. São empresas fortemente baseadas em gastos com pesquisa e desenvolvimento e posteriormente ao desenvolvimento de um novo produto preservam sua vantagem competitiva, mesmo que temporariamente, através de marcas e patentes.

A literatura financeira, também, ressalta a importância da questão de perda de flexibilidade que decorre do fato de se trabalhar com alto endividamento. Empresas muito endividadas perdem a possibilidade de tomar novas dívidas caso necessitem de recursos para financiar novos investimentos que surgem inesperadamente. Por conta disso, muitas empresas trabalham com menos dívidas do que gostariam, preservando um potencial de tomada de dívidas adicionais, caso seja necessário. As empresas que tendem a valorizar mais essa questão da flexibilidade são aquelas que estão em franco crescimento, atuando em novos negócios e sujeitas a se depararem com projetos atraentes do ponto de vista de geração de retorno. Também, quanto maior for a incerteza em relação ao surgimento de projetos futuros, mais importante se torna a questão da flexibilidade, o que normalmente acontece com negócios não maduros e pouco consolidados.

Empresas em setores relacionados com alta tecnologia (Intel e Microsoft, por exemplo), que apresentam grande incerteza e potencial de alto retorno em seus investimentos, tendem a trabalhar com pouca dívida em suas estruturas de capital.

Outra teoria que foi desenvolvida no campo da estrutura de capital por Myers (1984) é denominada de Pecking Order, ou da ordem de preferência, que leva em conta a assimetria de informação que existe no mercado de capitais, à medida que os administradores da empresa são mais bem informados do que os investidores, de uma forma geral, em relação às tendências dos negócios da empresa (MYERS e MAJLUF,1984).

Segundo a teoria do Pecking Order, os administradores da empresa estabelecem uma ordem de preferência entre os recursos passíveis de utilização, preferindo, em primeiro lugar, utilizar recursos gerados internamente; em segundo lugar, captar recursos por meio de novas dívidas e, em úl- 
timo lugar, captar recursos por meio do lançamento de novas ações. Essa ordem de preferência está fundamentada no fato de que recursos gerados internamente não têm custos de transação e no fato de que a emissão de novas dívidas tende a sinalizar uma informação positiva sobre a empresa, enquanto a emissão de novas ações tende, ao contrário, a sinalizar uma informação negativa. Reconhecendo que os administradores possuem melhores informações do que os investidores do mercado, sempre que os administradores anunciam uma nova captação de recursos, tal anúncio sinaliza aos investidores alguma informação que eles não possuem. Por exemplo, o anúncio da emissão de novas ações sinaliza para o mercado que os preços das ações da empresa devem estar superavaliados, fazendo com que caiam em conseqüência do anúncio.

Neste estudo, considera-se a variável rentabilidade operacional da empresa (Prof) como proxy da preferência pelo uso de recursos gerados internamente vis-à-vis à emissão de novas dívidas. Considera-se a variável logaritmo da receita operacional líquida (Size) como uma proxy do tamanho da empresa. Empresas de maior porte tendem a ter um maior nível de endividamento em decorrência de três aspectos pelo menos. Em primeiro lugar, empresas maiores têm condições de resolver os problemas de assimetria de informação entre credores e devedores com menores custos. Em segundo lugar, empresas maiores pagam proporcionalmente custos mais baixos na captação externa de recursos. Em terceiro lugar, empresas de maior porte, normalmente, são mais diversificadas, possuindo, dessa forma, menor risco de negócio.

Considera-se, ainda, com base na teoria do Pecking Order, a variável crescimento das vendas (Crescrda) como proxy do crescimento da empresa, à medida que empresas com maiores taxas de crescimento tendem a procurar fora os recursos para financiar o seu crescimento, privilegiando em primeiro lugar a tomada de novas dívidas. No entanto, Gaud, Jani, Hoesli e Bender (2005) obtiveram resultados apontando para uma relação negativa entre crescimento e endividamento, no caso de empresas suíças.

$\mathrm{O}$ indicador de liquidez corrente, de acordo com Ozkan (2001), possui um impacto misto na estrutura de capital, podendo o sinal tanto ser positivo como negativo. Empresas com alto grau de liquidez corrente poderiam comportar maior grau de endividamento externo, pois teriam melhores condições para efetuar o pagamento dos empréstimos quando devido. Já as empresas com maior liquidez em seus ativos poderiam utilizá-los para financiar seus investimentos. Uma explicação para quando ocorre esse sinal negativo, segundo Prowse (1990 apud Ozkan, 2001) demonstrando a extensão da possibilidade de expropriação dos credores por parte dos acionistas no uso dos ativos líquidos.

Segundo Harris e Raviv (1991) e Titman e Wessels (1988), ativos tangíveis tendem a ter maior valor de liquidação em situações de dificuldades financeiras, reduzindo problemas de seleção adversa e de moral hazard. Problemas de seleção adversa são, na verdade, problemas de agência, em que os acionistas fazem uso do seu poder de decisão, expropriando riqueza dos credores a seu favor, especialmente em situações de crise financeira. Ross, Westerfield e Jaffe (2002), dentre outros, ilustram bem esses casos. Portanto, fornecedores de dívida tendem a se sentirem mais confortáveis quando ativos tangíveis são dados em garantia de empréstimos, fazendo com que a empresa tenha maior capacidade de tomada de dívidas e a custos financeiros menores.

Convém destacar que empresas de menor porte magnificam os problemas de agência entre credores e acionistas, pois empresas menores são mais flexíveis e dessa forma podem aumentar o risco de seus projetos de investimento com mais facilidade. Um outro aspecto a ser considerado é que essas empresas, normalmente, são administradas pelos seus principais acionistas, o que lhes dá maior incentivo para agirem em benefício próprio em detrimento dos credores.

Ainda levando-se em conta os problemas de seleção adversa e de agência, é esperado que as empresas com muitas oportunidades de investimentos sejam menos endividadas, ou que sejam mais endividadas no curto do que no longo prazo. Uma das variáveis que é tomada como proxy de oportunidades de investimento futuras é o índice valor de mercado sobre valor contábil da empresa, assim como os gastos com pesquisa e desenvolvimento. Tomouse, neste estudo, somente a primeira proxy, dada a impossibilidade de obtenção de informações dos gastos realizados com PED nas demonstrações financeiras publicadas.

Evidências empíricas em relação à relevância do tamanho, como variável explicativa do endividamento das empresas, podem ser obtidas nos trabalhos de Gaud, Jani, Hoesli e Bender (2005), Marsh (1982), Ferri e Jones (1979) e Titman e Wessels (1988). Evidências em relação ao grau de imobilização são encontradas em Long e Malitz (1985) e Gaud, Jani, Hoesli e Bender (2005).

Ferri e Jones (1979), Bradley, Jarrell e Kim (1984), Titman e Wessels (1988), Scott (1972) e Scott e Martin (1976) sugerem que o setor de atividade em que a empresa opera é uma variável relevante para explicar a estrutura financeira da empresa. Em face dos resultados de estudo recente realizado no Brasil (NAKAMURA, MARTIN e KIMURA, 2004), que concluiu que o setor de atividade em que a empresa opera não tende a apresentar relevância estatística na determinação da estrutura de capital, resolveu-se não utilizar variáveis dummies, por setores, neste estudo. Ross, Westerfield e Jaffe (2002) apresentam resultados que confirmam a validade da teoria do Pecking Order tanto no caso de empresas norte-americanas quanto no de empresas japonesas. Myers e Sunder (1999), também, verificaram a validade da teoria do Pecking Order considerando uma amostra de empresas maduras.

De acordo com Titman e Grinblatt (2002) empresas que estão gerando lucros substanciais antes de juros e impostos devem usar um montante significativo de dívidas para obterem as vantagens da dedutibilidade dos juros para fins de imposto de renda. Porém, de acordo com evidências em- 
píricas obtidas por Kester (1986), empresas mais rentáveis tendem a manter um nível de endividamento mais baixo, resultado esse confirmado por Gaud, Jani, Hoesli e Bender (2005). Além disso, Fama e French (1998) descobriram que é difícil avaliar o impacto das economias fiscais relacionadas à dedução dos juros no valor da empresa.

Titman e Wessels (1988), também, não observaram relação positiva, em um estudo cross-section, entre lucro antes de juros e impostos e endividamento, pelo contrário. Isso pode ser justificado pelo fato de que as empresas financiam novos investimentos predominantemente com dívidas. Uma outra justificativa seria a de que as empresas que apresentam desempenho pobre (lucro antes de juros e impostos baixo ou negativo) tendem a bancar suas despesas acumulando dívidas.

Estudo de MacKie-Mason (1990) descobriu que as empresas consideram benefícios fiscais quando decidem emitir montantes substanciais de novas dívidas ou de novas ações. É mais provável que as empresas que estão menos aptas a fazer uso da dedução de juros emitam ações ao invés de dívida. Por outro lado, empresas com lucros tributáveis substanciais estão mais propensas a emitir dívidas.

Graham (1996) descobriu que empresas com altas alíquotas marginais de impostos são mais propensas a elevar seu endividamento do que empresas com baixas alíquotas marginais de impostos.

Givoly, Hayn, Ofer e Sarig (1992) examinaram o impacto da Tax Reform Act de 1986 nos Estados Unidos, que reduziu o nível de benefícios fiscais não relacionados a dívidas para a maioria das empresas. Eles descobriram que as empresas que mais perderam benefícios aumentaram seus níveis de dívida do que as que foram menos afetadas pela reforma.

Estudo desenvolvido, no Brasil, por Zani e Ness Jr. (2000) indicam que a instituição dos juros sobre capital próprio, nos anos 90 , reduziu a carga fiscal das empresas mas não a ponto de estimular um maior uso de capital próprio em detrimento de capital de terceiros. Vale ressaltar que os juros sobre capital próprio funcionam como dividendos pagos aos acionistas, sendo, ao contrário dos dividendos, dedutíveis para fins fiscais.

Um estudo de Weiss (1990) sobre falências de grandes empresas constatou que os custos diretos de falência, da empresa em processo falimentar, estão em torno de 3,1\% do valor total da dívida e do capital próprio. Dado que os custos diretos de falência são os mesmos para empresas pequenas e grandes, os custos de falência das pequenas, em proporção aos seus ativos, são muito maiores. Para empresas pequenas, esses custos podem ser muito expressivos, podendo chegar de 20 a $25 \%$ do valor da empresa. Essa é mais uma justificativa para as empresas maiores serem mais endividadas.

Nakamura (1992), baseado numa amostra representativa de empresas brasileiras, de capital aberto e fechado e baseando-se em dados contábeis dos anos 80 , identificou a relevância das variáveis tamanho e grau de imobilização como explicativas do nível de endividamento geral das empresas. Ao mesmo tempo, através de análise de variância, verificou que a classificação setorial ajuda a discriminar a forma como as empresas estabelecem sua política de endividamento.

Famá e Kayo (1997), tomando o período de 1992 a 1996, obtiveram evidências de que as empresas optam pelo maior uso de capital próprio, quando existem boas oportunidades de crescimento, enquanto as empresas de baixo crescimento tendem a utilizar mais intensamente capital de terceiros, o que confirma a teoria.

Moreira e Puga (2001), analisando o período de 1995 a 1997, encontraram evidências que favorecem a teoria do Pecking Order. Ao mesmo tempo, verificaram que empresas mais intensivas de capital são mais endividadas, confirmando resultados anteriores. Ainda nesse estudo verificaram que empresas estrangeiras são mais endividadas e empresas de menor porte dependem mais de recursos próprios, o que pode ser justificado pela conjuntura econômica prevalecente no Brasil nos últimos anos, marcada por escassez de financiamentos, principalmente de longo prazo e também, primordialmente, para pequenas empresas.

Famá e Perobelli (2001) replicaram estudo desenvolvido por Titman e Wessels (1988), utilizando a técnica de análise fatorial a fim de identificar determinantes dos endividamentos de curto e longo prazo das empresas. Foram encontradas relações negativas entre crescimento dos ativos, tamanho e lucratividade com o grau de endividamento de curto prazo. Em relação a endividamento de longo prazo não foram observados resultados significantes.

Gomes e Leal (2001) desenvolveram estudo relativo ao período de 1995 a 1997, considerando os fatores: tamanho, tangibilidade, crescimento, risco e setor industrial. Encontraram relação positiva entre endividamento e os fatores tangibilidade e risco, bem como relação inversa entre endividamento e os fatores rentabilidade, crescimento e tamanho. Observe-se que os resultados em relação a risco e tamanho contrariam as teorias prevalecentes. Em relação à classificação industrial, os resultados mostraram-se não significantes.

Terra (2002) desenvolveu estudo sobre estrutura de capital utilizando-se da análise de dados em painel e tomando dados no período de 1986 a 2000. Tal pesquisa abordou sete países latino-americanos, incluindo o Brasil, e as variáveis tangibilidade, rentabilidade, tamanho, oportunidades de crescimento, economias fiscais e risco. Rentabilidade apresentou resultados consistentes entre os países e também entre diferentes medidas de endividamento. Tais resultados foram a favor da teoria do Pecking Order, indicando relação negativa e substancial. Observaram-se relações positivas entre oportunidades de crescimento e endividamento, porém não de forma conclusiva.

Santana e Turolla (2002) desenvolveram estudo, abarcando dados do período de 1991 a 2000, referente ao setor petroquímico e fazendo uso de análise de regressão. Dezenove empresas foram abordadas. Os autores concluíram que estratégias de Pecking Order não apresentaram superioridade em relação a estratégias de Trade-off. 
Brito e Lima (2003), analisando o período de 1995 a 2001, verificaram que as empresas menores se endividam mais e no curto prazo. A verificação de relação positiva entre o fator de tangibilidade e o endividamento total e de longo prazo confirmam a teoria do Pecking Order. Também a relação positiva de crescimento com endividamento e a relação negativa de rentabilidade com endividamento, também, favorecem a teoria do Pecking Order. Os resultados em relação ao fator risco mostraram-se inconclusivos.

Brito e Silva (2003), abordando dados de cento e onze empresas não financeiras no período de 1995 a 2001, verificaram que as mais lucrativas são menos endividadas. Empresas que investem menos, igualmente, são menos endividadas. Ambos os resultados estão de acordo com as teorias prevalecentes.

Terra (2003) estudou a influência de fatores macroeconômicos sobre o endividamento das empresas considerando uma amostra de sete países latino-americanos (inclusive o Brasil) e abrangendo o período de 1986 a 2000. A técnica de panel data foi aplicada a diversas medidas de alavancagem. Os resultados contrariam estudos anteriores, sugerindo que fatores macroeconômicos específicos de cada país não são determinantes do endividamento das empresas. Na verdade, fatores específicos das empresas mostraram-se mais significativos como indicadores da estrutura de capital das empresas.

Mellone Jr. (2003) tomou o beta das ações como medida de risco para 187 empresas de capital aberto no ano de 2001 e concluiu pela não significância desse fator para a escolha da estrutura de capital das empresas. O estudo foi feito baseado na hipótese de que o controlador da empresa diversifica o seu risco através de mudança na estrutura de capital, elevando o grau de endividamento.

Nakamura e Mota (2002) desenvolveram pesquisa de campo junto a executivos financeiros de grandes empresas brasileiras (total de 94 respondentes) praticamente replicando o trabalho desenvolvido por Pinegar e Wilbricht (1989) e verificaram que as empresas brasileiras tendem a seguir a teoria do Pecking Order na tomada de decisão de política de endividamento.

Nakamura, Martin e Kimura (2004) desenvolveram estudo empírico tomando dados recentes de empresas de capital aberto do Brasil, observando a significância estatística especialmente das variáveis rentabilidade e grau de imobilização como explicativos do endividamento.

\section{DADOS, VARIÁVEIS E MODELO EMPÍRICO}

\subsection{Dados}

As bases de dados utilizadas para as análises provêm do banco de dados Economática Pro ${ }^{\circledR}$, que fornece tanto dados contábeis como de mercado. Inicialmente, foram levantadas companhias abertas de diversos setores de atividade, listadas na Bolsa de Valores de São Paulo, com exceção de Bancos, Companhias de Seguro e holdings, no período de 1998 a 2003. Todos os dados das empresas com dados faltantes (missing) foram eliminados, só permanecendo, na análise, as empresas que possuíam cinco anos seguidos de observações (o ano de 1998 não foi utilizado devido à impossibilidade de cálculo da variável crescimento. Essa impossibilidade decorreu da indisponibilidade dos dados do ano de 1997 necessários à realização desse cálculo). Dessa forma, foram selecionadas 91 empresas com cinco anos de informações, ou 455 observações de cada indicador estudado. Essa quantidade de dados está em linha com o artigo de Gaud et al. (2005) que apresenta 104 empresas suíças num total de 946 observações em seis anos, e um pouco inferior ao artigo de Ozkan (2001) em um período de doze anos com 390 empresas e 4.132 observações.

\subsection{Variáveis}

Neste estudo, são utilizadas proxies das variáveis explanatórias dos determinantes da estrutura de capital, seguindo os padrões estabelecidos por estudos internacionais anteriores (Miguel e Pindado (2001), Gaud et al. (2005) e Ozkan (2001), conforme as Tabelas 10 e 20.

A exemplo de Gaud et al. (2005) serão usadas duas proxies para medir a alavancagem financeira. A primeira proxy (Dtab) refere-se ao valor contábil apenas e é definida pela razão entre capital de terceiros e total de passivos. A outra proxy (Dtam) é baseada na capitalização a mercado do patrimônio liquido. Segundo Titman e Wessels (1988), esse procedimento permite o controle de possíveis correlações espúrias entre a interpretação de alavancagem e da prática gerencial efetiva. É importante que se obtenha, portanto, o mesmo sinal nas variáveis significativas.

As oportunidades de crescimento foram analisadas sob dois ângulos: as geradas e interpretadas pelo mercado (Mtb) e a gerada pelo crescimento recente das vendas (Crescrda).

Para medir o tamanho das empresas, utilizou-se o logaritmo natural da receita operacional liquida. Trata-se da

Tabela 1 | Variável Dependente

\begin{tabular}{l|c|c}
\multicolumn{1}{c|}{ Variável } & Sigla & Definição Operacional \\
\hline Endividamento a mercado & Dtam & Dividas Totais / Ativos Totais (a mercado) \\
\hline Endividamento contábil & Dtab & Dividas Totais / Ativos Totais (contábil)
\end{tabular}

Fonte: os autores. 
Tabela 2 Variáveis Independentes

\begin{tabular}{|c|c|c|}
\hline Variável & Sigla & Definição Operacional \\
\hline Índice de Liquidez corrente & Liqcorr & Ativo Circulante/ Passivo Circulante \\
\hline Tamanho da Empresa & Size & LN da Receita Operacional Líquida \\
\hline Rentabilidade & Prof & EBITDA / Ativos Totais \\
\hline $\begin{array}{l}\text { Crescimento Esperado pelo diferencial de } \\
\text { valor de Mercado }\end{array}$ & Mtb & Valor de Mercado dos Ativos / Valor Contábil dos Ativos \\
\hline $\begin{array}{l}\text { Risco do Negócio medido pela volatilidade } \\
\text { de lucros }\end{array}$ & Pld & (Desvio-Padrão Ebit - Média)/ Receita Operacional Liquida \\
\hline Economia Fiscal & Ecnd & (Depreciação + Amortização) / EBITDA \\
\hline Crescimento das Vendas & Crescrda & $\begin{array}{l}\text { (Receita Operacional Liquida Ano } 1 \text { - Receita Operacional Liquida } \\
\text { Ano 0) / Receita Operacional Liquida Ano } 0\end{array}$ \\
\hline
\end{tabular}

Fonte: os autores.

proxy mais comumente utilizada. (TITMAN e WESSELS, 1988, RAJAN e ZINGALES, 1995 e OZKAN, 2001).

Para medir a rentabilidade, foi usada a variável Prof, razão entre LAJIRDA ou EBITDA e os ativos totais, em linha com Miguel e Pindado (2001), Ozkan (2001) e Gaud et al. (2005).

De forma consistente com os artigos internacionais mais recentes (GAUD et al., 2005), havia sido considerada, inicialmente, uma variável de tangíveis usados como uma proxy para garantias colaterais. Essa variável (Tang), que consiste na relação entre os ativos tangíveis totais mais estoques e o total dos ativos, foi eliminada do painel porque os modelos rodados com essa variável mostraram problemas de multicolinearidade.

Ainda consistente com os mesmos artigos, definira-se a variável independente Fdc (Financial distress cost) como uma proxy de risco. Além dessa, utilizou-se a medida tradicional do risco $(\mathrm{Cv})$, ou coeficiente de variação e o Pld (medindo a variabilidade do LAJIR (Ebit) dividido pela receita operacional). Novamente, por problemas de multicolinearidade, foi mantido, apenas, o PId como proxy de risco medida através da "volatilidade financeira".

\subsection{Modelo Empírico (PANEL DATA)}

Não existe ainda um modelo definitivo que relacione a estrutura de capital e seus determinantes. Nesse caso, poder-se-ia correr o risco de ter um modelo com problemas de especificação. Para lidar com esse problema, o método de painel (combinação de dados de corte transversal com séries temporais) foi escolhido, pois consegue eliminar o efeito de variáveis omitidas, mesmo sem observá-las de fato, através do estudo de variações na variável dependente ao longo do tempo, se forem constantes. Consistente com o fato de os dados serem referentes às mesmas empresas nos anos, no recorte longitudinal, não se podendo assumir que as observações sejam independentes para a finalidade de análise econométrica (WOOLDRIDGE, 2003).

Poder-se-ia pensar se a técnica desenvolvida adaptase bem a ambientes turbulentos como o nosso. De fato, encontra-se na literatura internacional recente, a aplicação dessa técnica em países e economias bastante diferentes.
Os artigos vão de Ozkan (2001) no Reino Unido, Colombo (2001) na Hungria, Frangouli (2002) na Grécia, Bhole e Mahakud (2004) na Índia e Gaud et al. (2005) na Suíça com resultados ainda não consolidados de forma teórica.

De acordo com Baltagi (1999), através da analise de empresas de diferentes setores pode-se obter uma estimação mais eficiente dos parâmetros com pressupostos menos restritivos. Além disso, pode-se detectar melhor as diferenças entre as empresas ou grupo de empresas (heterogeneidade). É possível, também, observar a dinâmica das variáveis explicativas ao longo do tempo. Assim sendo, se os parâmetros não variarem ao longo do tempo, será possível reunir os dados (pooling) e aplicar o método de Mínimos Quadrados Ordinários ao processo de estimação.

Entretanto, nesse modelo poderá ocorrer uma restrição comum aos modelos de corte transversal que é a heteroscedasticidade do termo erro (por exemplo, a variância do termo erro poderá ser maior quanto maior for o tamanho das empresas). Igualmente, no caso das séries temporais, o termo erro das diferentes observações poderá estar correlacionado em série.

Finalmente, poderá existir uma combinação dos dois efeitos. Desse modo, a reunião dos dados já não será mais recomendada e será necessário considerar a presença da heteroscedasticidade e/ou da correlação serial.

Segundo Gaud et al. (2005), uma análise de dados por painéis permite estudar a natureza dinâmica das decisões de estrutura de capital no nível da firma, mas os modelos de efeitos fixos e aleatórios podem selecionar estimadores viesados e inconsistentes, pois o termo erro pode estar correlacionado com a variável defasada.

A estimativa do painel dinâmico requer alguns cuidados. Apesar de trabalhar-se com um painel equilibrado, com todas as observações de cada entidade e cada período de tempo, incorre-se no problema de ter apenas um curto período de análise. Anderson e Hsiao (1982 apud OZKAN) sugeriram uma técnica consistente de estimação, usando uma variável instrumental não correlacionada com os termos erros, caso esses não estejam correlacionados em série. Essa estimativa não levará necessariamente a estima- 
Tabela 3 Especificação dos estimadores utilizados neste estudo

\begin{tabular}{l|l|c}
\multicolumn{2}{c|}{ Estático (equação 1) } & Dinâmico (equação 1*) \\
OLS & EGLS & \\
\hline Dentro (within) & GLS (resid OLS) & 1 passo - com instrumento GMM \\
\hline Entre (between) & ML & 1 passo - sem instrumento GMM
\end{tabular}

Fonte: Doornik e Hendry (2001)

dores eficientes, pois o modelo de parâmetros não utiliza todas as condições de momento.

Dessa forma, a estimação através da técnica de GMM (Generalized Method of Moments ou Método dos Momentos Generalizado) passa a ser recomendada, pois ela permite a inclusão de efeitos específicos da empresa e dummies de tempo, constituindo-se em um instrumento eficiente de controle sobre a endogeneidade (OZKAN, 2001).

Dois modelos foram, portanto, testados: 1) Análise Longitudinal dos Dados Estática (Static Panel Data), com efeito fixo ou com efeito aleatório e 2) Análise Longitudinal dos Dados Dinâmica (Dinamic Panel Data). Em seguida, foram testadas as regressões usando as variáveis instrumentais e o $\mathrm{GMM}$ e o $\mathrm{AH}$ (Anderson Hsiao), reportados com ambas as proxies de alavancagem, para efeito de comparação.

Com relação ao Painel Estático, o de efeito fixo considera que a heterogeneidade característica de uma empresa ou grupo de empresas é constante e impacta somente no intercepto, seja em um determinado instante, seja ao longo do tempo. Já o Painel Estático de efeito aleatório considera a heterogeneidade das empresas como variável, impactando nos resíduos da regressão. Por sua vez, quando as variáveis explicativas estão correlacionadas com o termo erro, o modelo de painel dinâmico deve ser utilizado. Só estão reportados os resultados da variável Dtam (proxy de alavancagem de mercado) pois os resultados são similares.
Seja, portanto:

$$
Y_{i t}=x^{\prime} \beta_{i t}+\gamma_{t}+\eta_{i}+\varepsilon_{i t}, \quad \text { eq. (1) Painel Estático }
$$$$
\operatorname{com~} \mathrm{i}=1, \ldots, \mathrm{N} \text { e } \mathrm{t}=1, \ldots, \mathrm{T} \text {. }
$$

$$
Y_{i t}=\sum_{K=1}^{P} \alpha_{k} \cdot y_{i,-k}+\beta^{\prime}(L) \cdot x_{i t}+\gamma_{t}+\eta_{i}+\varepsilon_{i t^{\prime}}
$$

eq $\left(1^{\star}\right)$ Painel Dinâmico

$$
\operatorname{com} \mathrm{i}=1, \ldots, \mathrm{N} \text { e } \mathrm{t}=\mathrm{q}+1, \ldots, \mathrm{T} \text { em que: }
$$

$Y_{i t}=$ endividamento; $x_{1 i t}=$ vetor das variáveis explicativas; $\eta_{\mathrm{i}}=$ heterogeneidade devido ao fator empresa (corte transversal); $\gamma_{\mathrm{t}}=$ heterogeneidade devido ao fator tempo (corte longitudinal); $\mathrm{L}=$ operador defasagem; $\mathrm{q}=$ defasagem máxima do modelo e $\mathrm{O}=\mathrm{N}$. $\mathrm{T}$.

Os subscritos i e t referem-se à empresa e ao tempo, respectivamente, e os $\beta$ 's e os $\alpha$ 's são os parâmetros da regressão.

Se $\eta_{\mathrm{i}}$ for constante, obtém-se o modelo com efeito fixo. Por outro lado, se $\eta_{\mathrm{i}}$ for variável, obtém-se o modelo com efeito aleatório.

Ainda em Doornik e Hendry (2001), tem-se a especificação dos estimadores utilizados, conforme Tabela $3 \mathbf{0}$.

\section{RESULTADOS}

As Tabelas 40 e 50 apresentam os resultados da aplicação dos modelos de Análise Longitudinal dos Dados Es- tática (Static Panel Data) e Análise Longitudinal dos Dados

\begin{tabular}{|c|c|c|c|c|}
\hline & OLS (Polled) & OLS (Pooled Diff) & OLS Within & OLS Between \\
\hline Liqcorr & $-0.105637^{*}$ & $-0.0687461 *$ & -0.104681 * & $-0.115055^{* *}$ \\
\hline Size & -0.0257785 & -0.0360624 & -0.0434094 & -0.0151610 \\
\hline Prof & $-0.95303 * * *$ & -0.327175 & -0.398979 & $-118.004^{* *}$ \\
\hline Mtb & $-0.0639260 *$ & $-0.0175409 *$ & $-0.015268^{*}$ & $-0.081387^{\star}$ \\
\hline Pld & $-0.0049438 * * *$ & $-0.00955360 *$ & $-0.010951^{*}$ & 0.00866075 \\
\hline Ecnd & -0.00607212 & -0.00129270 & -0.0097075 & 0.0147337 \\
\hline Crescvda & $-0.0057327^{*}$ & $-0.0029464^{*}$ & $-0.0039845^{*}$ & $-0.015524^{* *}$ \\
\hline$R^{2}$ & 0.5299746 & 0.169199 & 0,2226557 & 0,6791209 \\
\hline$W(j)$ & * & * & * & * \\
\hline
\end{tabular}
Dinâmica (Dynamic Panel Data).

Tabela 4 Estimativa dos Parâmetros - Variável Dependente LDtam 
Tabela 5 | Estimativa dos Parâmetros - Variável Dependente Ldtam

\begin{tabular}{|c|c|c|c|}
\hline $\begin{array}{l}\text { Modelo } \\
\text { Variável }\end{array}$ & $\begin{array}{c}\text { GLS } \\
\text { Within/Between }\end{array}$ & $\begin{array}{c}\text { GLS } \\
\text { Residuals }\end{array}$ & ML \\
\hline Liqcorr & $-0.103863^{*}$ & $-0.103702^{*}$ & $-0.104086^{\star}$ \\
\hline Size & $-0.0456358^{* *}$ & $-0.043422^{*}$ & $-0.046284^{* *}$ \\
\hline Prof & $-0.487253^{* *}$ & $-0.553638 * *$ & $-0.444407^{* *}$ \\
\hline Mtb & $-0.025094^{*}$ & $-0.031234^{*}$ & $-0.020823^{*}$ \\
\hline Pld & $-0.0105799 * *$ & $-0,0099971 * *$ & $-0.010889 * *$ \\
\hline Ecnd & -0.00963053 & $-0,00946203$ & $-0,0097433$ \\
\hline Crescrda & $-0,00404459 *$ & $-0,00411464^{*}$ & $-0,00401324^{*}$ \\
\hline$W(j)$ & * & * & * \\
\hline
\end{tabular}

As evidências são contrárias ao efeito fixo $\left(\mathrm{F}_{\mathrm{obs}}=\right.$ 1,56). Para tanto, realizou-se o teste F proposto por Greene (2000), em que a hipótese nula se refere à significância conjunta do efeito fixo, a seguir definido:

$$
F(N-1, N T-N-K)=\frac{\left(R_{W}^{2}-R_{p o l}^{2}\right) /(N-1)}{\left(1-R_{W}^{2}\right) /(N T-N-K)}
$$

A seguir, foi feito o teste Breusch-Pagan, em que a hipótese nula se refere à não autocorrelação dos resíduos (e):

$$
L M=\frac{N T}{2(T-1)} \cdot\left(\frac{T^{2 \bar{e}^{\prime} \bar{e}}}{e e^{\prime}}\right)
$$

O resultado obtido $(L M=55,49)$ implicou na rejeição da hipótese nula (não houve autocorrelação). Isso implica em evidências a favor do efeito aleatório.

Entretanto, ao se realizar o teste Hausman que compara os estimadores de efeito fixo e aleatório, constata-se que os erros estão correlacionados com as variáveis explicativas tanto para Ldtam (acima reportado) como para Ldtab. Conclui-se que os estimadores são inconsistentes. Para resolver esse problema, utiliza-se o painel dinâmico, conforme reportado, a seguir, na Tabela $6 \bullet$, com instrumentos de GMM e de $\mathrm{AH}$.

Ao se utilizar o GMM como instrumento, com exceção de quatro variáveis (Size, Size ${ }_{-1}$, Pld) não significativas e $\mathrm{Pld}_{-1}$ todas as relações entre alavancagem, medida por Ldtam $_{-1}$ e Ldtab $_{-1}$ e as variáveis independentes apresentaram mesmo sinal, o que confirma a escolha de uma proxy representativa do que se deseja medir (TITMAN e WESSELS, 1988). Já o uso do $A H$ não apresentou esse mesmo nível de aderência.

De modo geral, o teste Wald de significância conjunta dos regressores e das dummies de tempo (com GMM e AH) e o Sargan (com GMM) mostraram-se significantes ao nível de $1 \%$. Pode-se concluir, portanto, que os instrumentos não estão correlacionados com o termo erro e, conseqüentemente, pela adequação dos instrumentos usados.
Ainda de modo geral, a inversão de sinais observada entre as variáveis e suas versões defasadas (com exceção apenas das variáveis Crescvda no GMM e Pld, Ecnd e Crescvda no $\mathrm{AH}$ ) sugere que existe uma dinâmica de adequação de curto prazo (apenas um ano) em relação à estrutura de capital. Muitas vezes, o efeito é parcialmente ou até completamente anulado, verificado pelos coeficientes como, por exemplo, em Liqcorr e Liqcorr ${ }_{-1}$ ou Mtb e Mtb Lssa $_{-1}$ dinâmica está em linha com a teoria do Trade-off e não diverge da teoria do Pecking Order.

Seguem abaixo os resultados das regressões das variáveis, reunidas por defasagem para efeitos de análise. Serão destacados os resultados com GMM e somente quando citados, com $\mathrm{AH}$, devido ao maior poder do instrumento.

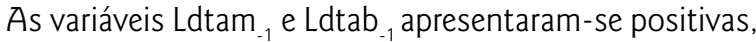
significativas em cada caso ao nível de 1\% (0,90 e 0,86 respectivamente no GMM e 0,96 e 0,92 no AH). Essa variável, segundo Ozkan (2001), é representada por 1- $\alpha$, em que $\alpha$ é a velocidade de ajuste. Miguel e Pindado (2001) explicam que o valor baixo encontrado no mercado espanhol $(0,21)$, representando, portanto, um alto coeficiente $(0,79)$, pode ser explicado pelo fato de as empresas espanholas terem um custo baixo de transação, reduzindo o custo de agencia entre credores e acionistas e aumentando a velocidade de ajuste. Já, essas variáveis são altas em diversos países, como reportam Gaud et al. (2005), como 0,72 na França ( $\alpha$ de 0,28 ) e entre 0,613 e 0,86 na Suíça ( $\alpha$ s respectivos de 0,387 e 0,14$)$. No caso brasileiro, esse alto valor da variável (de $0,86$ a 0,90$)$ geraria uma velocidade baixa de ajuste (entre $0,10$ e 0,14$)$, podendo ser reflexo das altas taxas de juros e da dificuldade de acesso ao crédito em nosso país.

Liqcorr e Liqcorr $_{-1}$ : O coeficiente das regressões dos índices de liquidez corrente (Liqcorr) apresentou sinal negativo com significância, em todos os casos. Já o indicador defasado (Liqcorr ${ }_{-1}$ ) apresentou sinal inverso e significativo para Ldtab. Esse fato pode estar relacionado com a possibilidade de uso de ativos com maior grau de liquidez para financiar os investimentos das empresas, no curto prazo ao invés de se recorrer às novas dívidas. Essa hipótese é compatível com o cenário econômico brasileiro de escassez de recursos e de altas taxas de juros. 
Size e Size .: $_{\text {: }}$ variável Size apresentou uma correlação negativa e significativa com a alavancagem apenas no modelo com defasagem da variável Ldtam, ou seja, o tamanho passado da empresa influencia mais significativamente a relação de alavancagem do que o tamanho atual, e de forma positiva, em linha, portanto, com as teorias de Pecking Order e de Trade-off bem como resultados de pesquisas anteriores, tais como as de Ozkan (2001) e Gaud et al. (2005). Interessante observar, também, que os coeficientes se anulam com as versões defasadas, verificado tanto com $\mathrm{CMM}$ como com $\mathrm{AH}$, demonstrando o ajuste pleno das empresas no curto prazo. (Vide Tabela $6 \mathbf{0}$ ).

Prof e Prof : $_{-1}$ Apenas Prof com GMM na regressão com Ldtab foi significativa e negativa, e com coeficiente elevado, sendo importante na regressão. Em linha com o Pecking Order, em que as empresas brasileiras com maior crescimento tenderiam a captar menos recursos, optando pelo recurso gerado internamente.

Mtb e Mtb $_{-1}$ : Essas variáveis apresentaram uma correlação negativa significativa com endividamento para Ldtam e Ldtab, pelo GMM. Esse resultado é consistente com as teorias de Pecking Order e Trade-off.

Pld e Pld : $_{-1}$ A variável Pld, que representa o risco de negócio, apresentou uma correlação negativa e significati- va para Ldtam e positiva para Ldtab. Sua versão defasada, apresentou comportamento inverso, sendo significativamente positiva para Ldtam e negativa para Ldtab. Essa ambivalência pode ser o resultado da própria reação do mercado em sua percepção do risco, medido por essa variável. Usando a variável Ldtam, mais correta na percepção de risco pois não se prende a definições contábeis como Ldtab, esse resultado é consistente com a teoria do Trade-off.

Ecnd e Ecnd : : A variável Ecnd, uma proxy da oportunidade de economia fiscal, não apresentou significância em nenhum dos modelos testados. Já a versão defasada, por sua vez, apresentou-se negativa e significativa, contrariando a expectativa teórica de alavancagem gerada por uso de beneficio fiscal. Essa proxy pode não ter conseguido capturar, adequadamente, o efeito conjunto das variáveis de planejamento tributário e não apenas as medidas pela depreciação e amortização.

Crescvda e Crescrda ${ }_{-1}$ A variável Crescvda ${ }_{-1}$, indicativa de crescimento do ano anterior, apresentou uma correlação positiva e significante com a alavancagem apenas na regressão da variável Ldtam. Esse resultado é consistente com a teoria do Pecking Order, mas dada sua dimensão e pouca significância, talvez tenha perdido poder explicativo do fator crescimento (para Mtb, por exemplo).

Tabela 6 || Estimativa dos Parâmetros - Variável Dependente Ldtam e Ldtab em Panel Dinâmico com GMM e com AH

\begin{tabular}{|c|c|c|c|c|}
\hline \multirow{2}{*}{$\begin{array}{c}\text { Proxy de } \\
\text { Alavancagem }\end{array}$} & \multicolumn{2}{|c|}{ Ldtam } & \multicolumn{2}{|c|}{ Ldtab } \\
\hline & $\begin{array}{c}\text { GMM com } \\
\text { Instrumento e } \\
\text { com Defasagem }\end{array}$ & $\begin{array}{l}\text { Anderson } \\
\text { Hsiao OLS }\end{array}$ & $\begin{array}{c}\text { GMM com } \\
\text { Instrumento e } \\
\text { com Defasagem }\end{array}$ & $\begin{array}{l}\text { Anderson } \\
\text { Hsiao OLS }\end{array}$ \\
\hline Ldtam & $0,902550 *$ & $0,961682 *$ & NA & NA \\
\hline Ldtab & NA & NA & $0,861187^{*}$ & $0,916402^{*}$ \\
\hline Liqcorr & $-0,0768177^{*}$ & $-0,0876458^{*}$ & $-0,0957132 *$ & $-0,0887853^{*}$ \\
\hline Liqcorr & 0,0447472 & $0,0462517 * * *$ & $0,0474280^{*}$ & $0,05334000 *$ \\
\hline Size & $-0,0536414$ & $-0,273092^{*}$ & 0,0622738 & 0,0173390 \\
\hline Size $_{-1}$ & $0,048740^{*}$ & $0,271265^{*}$ & $-0,0581727$ & $-0,0100077$ \\
\hline Prof & $-0,500720$ & 0,0904053 & $-0,628193^{*}$ & $-0,311304$ \\
\hline Prof $_{-1}$ & 0,181436 & $-0,313154$ & 0,372749 & 0,0265733 \\
\hline Mtb & $-0,0199629 *$ & $-0,0164470 *$ & $-0,00245062^{*}$ & $-0,00125717$ \\
\hline $\mathrm{Mtb}_{-1}$ & $0,0154952^{*}$ & 0,0113647 & $0,00553912^{*}$ & 0,00164062 \\
\hline Pld & $-0,171774^{*}$ & $-0,175021$ & $0,132217^{*}$ & 0,0615302 \\
\hline $\mathrm{Pld}_{-1}$ & $0,0315510^{*}$ & $-0,0132957$ & $-0,0223397^{*}$ & $-0,00977524$ \\
\hline Ecnd & $-0,00101767$ & $-0,0054666$ & $-0,00180233$ & 0,00696740 \\
\hline Ecnd $_{-1}$ & 0,00150832 & $-0,000383596$ & 0,00886348 & 0,00458193 \\
\hline Crescvda & 0,00219283 & $0,057595^{*}$ & 0,0015788 & 0,00299404 \\
\hline Crescrda $_{-1}$ & $0,00231569 *$ & $0,0174186^{*}$ & 0,00014565 & $0,0139072^{*}$ \\
\hline Constante & 0,0817382 & 0,06666 & $-0,0244908$ & $-0,0346319$ \\
\hline$W(j)$ & * & * & * & * \\
\hline Sargan & * & NA & * & NA \\
\hline
\end{tabular}

Fonte: os autores

* significante a $1 \% \quad * *$ significante a $5 \% \quad * * *$ significante a $10 \% \quad$ NA: não aplicável 


\section{CONCLUSÃO}

Este artigo procurou estudar os determinantes de estrutura de capital no Brasil, através da técnica estatística de painel (Panel Data), estático e dinâmico, incluindo a variável instrumental de momentos generalizados (GMM) e a Anderson Hsiao (AH). Para sua realização, foram levantados dados longitudinais e em corte de 91 companhias abertas listadas na Bolsa de Valores de São Paulo entre os anos de 1999 e 2003 a partir dos dados da Economática Pro ${ }^{\circledR}$. Como proxies de alavancagem, foram usados os conceitos contábil e de mercado, e seus resultados foram comparados. Em consonância com a literatura da área, foram selecionadas as seguintes variáveis: liquidez corrente, tamanho da empresa, rentabilidade, oportunidade de crescimento, risco de negócio, economia fiscal e crescimento de vendas, tangibilidade, coeficiente de variação e risco de falência. Após serem eliminadas as três últimas devido a problemas de multicolinearidade, foram feitos testes de Painel Estático com as duas versões da variável alavancagem, que revelou problemas de heteroscedasticidade de variáveis, fato comum nesse tipo de estudo. Posteriormente, foi realizada uma combinação com GMM e variáveis instrumentais para lidar com problemas de endogeneidade. Como instrumento comparativo, foi rodado o mesmo experimento com o instrumento $\mathrm{AH}$. O embasamento teórico da estrutura de capital sugere diversas interpretações, dentre as quais se destacam as teorias de Pecking Order e de Trade-off.

A teoria da Pecking Order sugere que as empresas seguem uma hierarquia de financiamento, valorizando flexibilidade e controle. Dessa forma, a dívida externa é fortemente preferida em relação ao patrimônio liquido como forma de financiamento. Assim, o tamanho das empresas (através da assimetria de informação), o crescimento de vendas teriam uma relação positiva com o endividamento. Por outro lado, fatores como rentabilidade e expectativa externa de crescimento teriam uma relação negativa com a alavancagem, conforme se verificou no estudo.

A teoria do Trade-off, por sua vez, advoga que existe uma estrutura ótima de capital, perseguida pelos administradores, ao decidir entre benefícios da dívida (fiscais e disciplinares) e seus custos (de falência, de agência e de flexibilidade). Assim, as variáveis rentabilidade, colaterais e planejamento tributário teriam efeito positivo, enquanto, expectativa de crescimento e volatilidade de resultados, efeito negativo. As duas últimas, também, foram encontradas no resultado deste estudo.

Dessa forma, os resultados obtidos através do Painel Dinâmico foram bastante consistentes com ambas as teorias de Pecking Order e de Trade-off. O uso de variáveis de controle para o estudo de alavancagem (contábil e de mercado) aliado a uma técnica robusta de análise (Panel Dinâmico com GMM e outro com $\mathrm{AH}$ ) atestam a robustez dos resultados obtidos no estudo.

O comportamento dos tomadores de decisão das empresas brasileiras segue, portanto, a lógica de escolha de flexibilidade e controle (Pecking Order), mas com uma dinâmica de ajuste de grau de endividamento ótimo de curto prazo (Trade-off). Como resultado complementar, a análise do painel dinâmico revela, ainda, que a velocidade do ajuste, dadas as restrições de comparabilidade, é menor do que em países como Estados Unidos e Inglaterra, Suíça e França. Diversos fatores devem ainda ser levados em conta, como diferenças de estabilidade econômica, de regras contratuais e de custo e escassez de capital, que também explicariam essa diferença entre países.

\section{Referências Bibliográficas}

BALTAGI, B. H.. Econometrics. 2.ed. Berlin: Springer, 1999.

BHOLE, L. M.; MAHAKUD, Jitendra. Trends and Determinants of Corporate Capital Structure in India: A Panel Data Analysis, Finance India, 18.1, Março 2004, pp. 37-55.

BRADLEY, Michael; JARRELL, Gregg A.; KIM, E. H.. On the Existence of an Optimal Capital Structure: Theory and Evidence, Journal of Finance, 39, Julho 1984, pp. 857-878.

BREALEY, Richard A.; MYERS, Stewart C.. Principles of Corporate Finance, 7 edition, McGraw-Hill Irwin, 2003.

BRITO, Ricardo D.; LIMA, Mônica R.. O Que Determina a Estrutura de Capital no Brasil?, Anais do 3‥ Encontro Brasileiro de Finanças, realizado de 21 a 22 de julho de 2003 , em São Paulo, SP.

; SILVA, Júlio César G. da, Testando as Previsões de Trade-Off e Pecking Order sobre Dividendos e Dívida para o Brasil, Anais do $3^{\circ}$. Encontro Brasileiro de Finanças, realizado de 21 a 22 de julho de 2003, em São Paulo, SP.

COLOMBO, Emilio. Determinants of corporate capital structure: evidence from Hungarian firms. Applied Economics, 33, 2001, pp 16891701.

DAMODARAN, Aswath. Corporate Finance, 2 edition, Wiley, 2001.

DOORNIK, J. A.; HENDRY, D. F.. Econometric Modelling Using PC Give. London: Timberlake, 2001.

FAMA, Eugene F.; FRENCH, Kenneth R.. Taxes, Financing Decisions and Firm Value, Journal of Finance, 53, Junho 1998, pp. 819-843.

FAMÁ, Rubens; KAYO, Eduardo K.. Teoria de Agência e Crescimento: Evidências Empíricas dos Efeitos Positivos e Negativos do Endividamento, Caderno de Pesquisas em Administração, v. 2, n. 5, pp.1-8, 1997. 
; PEROBELLI, Fernando Finotti C.. Fatores Determinantes da Estrutura de Capital: Aplicação a Empresas de Capital Aberto no Brasil, Anais do Primeiro Encontro Brasileiro de Finanças, realizado nos dias 23 e 24 de julho de 2001 em São Paulo, SP.

FERRI, Michael G.; JONES, Wesley H.. Determinants of Financial Structure: A New Methodological Approach, Journal of Finance, 34, Junho 1979, pp. 631-644

FRANGOULLI, Zoe. Capital Structure, Porduct differentiation and Monopoly Power: a Panel Method approach. Managerial Finance, 28, n. 5, 2002. pp 59-65.

GAUD, Philippe; JANI, Elion; HOESLI, Martin; BENDER, André. The capital structure of swiss companies: an empirical analysis using dynamic panel data. European Financial Management. Vol XI, n. 1, 2005, pp. 51-69.

GIVOLY, Dan; HAYN, Carla; OFER, Aharon; SARIG, Oded. Taxes and Capital Structure: Evidence from,Firm's Response to the Tax Reform Act of 1986, Review of Financial Studies, 5, 1992, pp. 331-55.

GOMES, Gabriel Lourenço; LEAL, Ricardo P. Câmara. Determinantes da Estrutura de Capitais das Empresas Brasileiras com Ações Negociadas em Bolsas de Valores. In Finanças Corporativas. São Paulo: Atlas, 2001.

GRAHAM, John. Debt and the MTR. Journal of Financial Economics, n. 41, 1996, pp. 41-73.

GREENE, William H.. Econometric Analysis, 4 ed. New Jersey: Prentice Hall, 2000.

HARRIS, Milton; RAVIV, Artur. The Theory of Optimal Capital Structure, Journal of Finance, n. 48, Março 1991, pp. 297-356.

JENSEN, Michael C.; MECKLING, William H.. Theory of the Firm: Managerial Behavior, Agency Costs and Ownership Structure, Journal of Financial Economics, n. 3, Outubro 1976, pp. 305-360

KESTER, W. Carl. Capital and Ownership Structure: A Comparison of United States and Japanese Manufacturing Corporations, Financial Management, n. 15, Spring 1986, pp. 5-16.

LONG, Michael S.; MALITZ, Ileen. The Investment-Financing Nexus: Some Empirical Evidence, Midland Corporate Finance Journal, n. 3, Fall 1985, pp. 53-59.

MACKIE-MASON, Jeffrey K.. Do Taxes Affect Corporate Financing Decisions? Journal of Finance, n. 45, Dezembro 1990, pp. 1471-1494. MARSH, Paul. The Choice Between Equity and Debt: An Empirical Study, Journal of Finance, n. 37, Março 1982, pp. 121-143.

MELLONE JR., Geraldo. Diversificação do Risco, Estrutura de Capital e de Controle: Um Estudo Empírico, Anais do $3^{\circ}$. Encontro Brasileiro de Finanças, realizado de 21 a 22 de julho de 2003, em São Paulo, SP.

MIGUEL, A.; PINDADO, J.. Determinants of Capital Structure: New Evidence from Spanish Panel Data, Journal of Corporate Finance, v. 7 , 2001, pp. 77-99.

MODIGLIANI, Franco; MILLER, Merton H.. Corporate Income Taxes and the Cost of Capital: A Correction, American Economic Review, 53, Junho 1963, pp. 433-443.

1958, pp. 261-297.

The Cost of Capital, Corporation Finance and the Theory of Investment, American Economic Review, 48, Junho

MOREIRA, Maurício Mesquita; PUGA, Fernando Pimentel. Como a Indústria Financia o seu Crescimento: uma Análise do Brasil Pós-Plano Real, Revista Econômica Contemporânea, v. 5, 2001, pp. 35-67.

MYERS, Stewart C.; MAJLUF, Nicholas S.. Corporate Financing and Investment Decisions When Firms Have Information Investors Do Not Have, Journal of Financial Economics, 13, Junho 1984, pp. 187-222.

; SUNDER, L. Shyam. Testing Static Tradeoff Against Pecking Order Models of Capital Structure, Journal of Financial Economics, 51, Fev. 1999, pp. 219-244.

. Determinants of Corporate Borrowing, Journal of Financial Economics, Vol. 5, 1977, pp. 147-175.

The Capital Structure Puzzle, Journal of Finance 39, Julho 1984, pp. 575-592.

NAKAMURA, Wilson Toshiro e MOTA, Almir da Silva, Decisões de Estrutura de Capital de Empresas Brasileiras: Um Estudo Empírico, Anais do CLADEA 2002, realizado em Porto Alegre, RS.

NAKAMURA, Wilson Toshiro, Estrutura de Capital das Empresas no Brasil: Evidências Empíricas, Dissertação de Mestrado em Administração, FEA-USP, 1992.

; MARTIN, Diógenes M. L. e KIMURA, Herbert, Novas Evidências sobre Estrutura de Capital no Brasil, Anais do CLADEA 2004, realizado em Puerto Plata, República Dominicana.

OZKAN, Aydin. Determinants of capital structure and adjustments to long run target: evidence from UK company panel data. Journal of Business Finance and Accounting. Jan/Mar 2001, pp. 175 - 199.

PINEGAR, J. Michael e WILBRICHT, Lisa, What Managers Think of Capital Structure Theory: A Survey, Financial Management, 18, Winter 1989, pp. 82-91

RAJAN, R. G. e ZINGALES, L. What Do We Know About Capital Structure? Some Evidence from International Data. Journal of Finance, 50.1995, pp.1421-60.

ROSS, Stephen A., WESTERFIELD, Randolph W. e JAFFE, Jeffrey F., Administração Financeira (Corporate Finance), São Paulo, Atlas,2002. 
SANTANA, José Ricardo e TUROLLA, Frederico, Escolha da Estrutura de Capital: Aplicação ao Caso do Setor Petroquímico Brasileiro no Período 1991-2000, Anais do XXVI ENANPAD, realizado de 22 a 25 de setembro de 2002, em Salvador, BA.

SCOTT Jr., David F. e MARTIN, John D., Industry Influence on Financial Structure, Financial Management, 4, Spring 1976, pp. 67-73.

. Evidence on the Importance of Financial Structure, Financial Management, 1, Summer 1972, pp. 45-50.

SHAPIRO, A., Modern Corporate Finance, 1989, New York, Macmillan.

STOCK, James, H. WATSON, Mark, W. Econometria. Pearson, 2004.

TERRA, Paulo Renato Soares, An Empirical Investigation on the Determinants of Capital Structure in Latin América, Anais do XXVI ENANPAD, realizado de 22 a 25 de setembro de 2002, em Salvador, BA.

. Are Macroeconomic Factors Important in Determining Capital Structuré? Evidence from Latin America, Anais do XXVII ENANPAD, realizado de 20 a 24 de setembro de 2003, Atibaia, SP.

TITMAN, Sheridan e GRINBLATT, Mark, Financial Markets and Corporate Strategy, 2nd Edition, McGraw-Hill Irwin, 2002.

; WESSELS, Roberto, The Determinants of Capital Structure Choice, Journal of Finance, 43, Março 1988, pp. 1-19.

. The Effect of Capital Structure on a Firm's Liquidation Decision, Journal of Financial Economics 13, 1984, pp. 1371-1375.

WEISS, Lawrence, Bankruptcy Resolution: Direct Costs and Violation of Priority of Claims, Journal of Financial Economics, 27, no. 2, 1990, pp. 285-314.

WOOLDRIDGE, Jeffrey, M. Introductory Econometrics. $2^{\text {nd }}$ edition,USA: Thomson, 2003.

ZANI, João e NESS JR., Walter Lee, Os Juros sobre o Capital Próprio versus a Vantagem Fiscal do Endividamento, Anais do $24^{\circ}$. Encontro da ANPAD, 2000 .

\section{NOTA - Endereço dos autores}

Universidade Presbiteriana Mackenzie Centro de Ciências Sociais e Aplicadas Rua da Consolação, 930 - Consolação São Paulo - SP 01302-090 